\title{
Herding in humans
}

\author{
Ramsey M. Raafat ${ }^{1,2}$, Nick Chater ${ }^{1,2}$ and Chris Frith $^{3,4}$ \\ ${ }^{1}$ Cognitive, Perceptual and Brain Sciences research department, University College London, Gower Street, London WC1E 6BT, UK \\ ${ }^{2}$ ESRC Centre for Economic Learning and Social Evolution (ELSE), Drayton House, Gordon Street, London WC1H OAN \\ ${ }^{3}$ Wellcome Trust Centre for Neuroimaging at University College London, 12 Queen Square, London WC1N 3BG, UK \\ ${ }^{4}$ Niels Bohr Project "Interacting Minds", Centre for Functionally Integrative Neuroscience, Aarhus University Hospital, \\ 8000 Aarhus C, Denmark
}

\begin{abstract}
Herding is a form of convergent social behaviour that can be broadly defined as the alignment of the thoughts or behaviours of individuals in a group (herd) through local interaction and without centralized coordination. We suggest that herding has a broad application, from intellectual fashion to mob violence; and that understanding herding is particularly pertinent in an increasingly interconnected world. An integrated approach to herding is proposed, describing two key issues: mechanisms of transmission of thoughts or behaviour between agents, and patterns of connections between agents. We show how bringing together the diverse, often disconnected, theoretical and methodological approaches illuminates the applicability of herding to many domains of cognition and suggest that cognitive neuroscience offers a novel approach to its study.
\end{abstract}

\section{Introduction}

Cognitive psychology generally focuses on the individual as the fundamental unit of analysis [1]. Nevertheless, we are all embedded in a complex system of social structures, which ground and organize much of our behaviour [2], ranging from national identity to religious affiliation. Here, we consider one of the many bridges that link agents and the social structures in which they are embedded: a form of convergent social behaviour termed 'herding'. Herding can be broadly defined as the alignment of thoughts or behaviours of individuals in a group (herd) through local interactions rather than centralized coordination. In other words, the apparent central coordination of the herd is an emergent property of local interactions.

Herding is an influential and well-documented feature of human behaviour in a number of domains, particularly economics and finance [3-5]. Although the current economic turmoil has revealed the depth of herding among financial institutions and individual investors [6,7] (and by implication the agents responsible for their decisions), this concept also has much broader relevance beyond the economic arena. Examples of phenomena that have been described as involving herd behaviour are diverse and varied, ranging from stock market bubbles and financial speculation to zealotry (e.g. the 2002 Gujarat mob violence [8]), political choice [9] and consumer preferences [10,11]. The concept is well known in ethology, where for example the biologist William Hamilton illustrated how herd behaviour can emerge from the uncoordinated behaviour of individuals engaged in predator avoidance [12]. The process has also

Corresponding author: Raafat, R.M. (r.raafat@ucl.ac.uk) been investigated in social psychology and terms such as Fad, Fashion, Mass Hysteria, Bandwagon Effect, Groupthink and Herd Instinct have entered common parlance.

Whereas the concepts behind herd mentality and herd behaviour have a rich history (Table 1), the methods, techniques and approaches currently used to elucidate them are relatively recent. In this article we review the extensive range of theoretical frameworks for describing herding. Similar ideas and explanations have emerged in many fields, albeit with different emphases, demonstrating the interdisciplinary nature of the concept. We propose a framework with which to organize these diverse approaches, which is based on a distinction between the mechanisms of transmission of a particular thought between individuals and the patterns of connections between individuals. We also distinguish between two main types of transmission: automatic contagion and rational deliberation. We suggest that cognitive neuroscience can reveal the mechanisms underlying the transmission of information, which can in turn help elucidate patterns of herd behaviour.

\section{Models of herding}

As indicated above, herding among individuals has been studied within a number of diverse domains. As a result, a number of different mechanisms and approaches have emerged across these domains in order to explain herding behaviour. It is therefore important to develop a conceptual framework within which the different approaches and models can be described, one that also permits the highlighting of common features. We propose that understanding how members of a group become aligned by 'local' interactions requires determining: (i) the mechanism of transmission that propagates a particular thought or behaviour from one agent to another and (ii) the pattern of interactions between agents. Conceptualizing herding as representing these two separate, though interconnected, perspectives addresses these requirements. Experimental approaches and modelling typically focus nearly exclusively on one issue or the other and this division between mechanisms of transmission vs. pattern of interactions between agents can be considered as a local vs. global division. This framework brings two primary questions into focus: (i) How do various types of information transmission, conscious vs. automatic, rational vs. emotional, affect the emergent architecture? (ii) What are the emergent effects of the pattern of connections?

Cognitive psychology and neuroscience generally focus on the individual, or on parts of the herd (Figure 1a), yet 
Table 1. A brief sampling of herding history

\begin{tabular}{|c|c|c|c|c|}
\hline & When & Discipline & Description & Mechanism \\
\hline Adam Smith & 1759 & Economics & $\begin{array}{l}\text { "As people imagine themselves in another's } \\
\text { situation," they display "motor mimicry" [87] }\end{array}$ & Motor mimicry \\
\hline Gustave Le Bon & 1895 & Psychology & $\begin{array}{l}\text { the "ancestral savagery...[of] the collective } \\
\text { mind" and the "loss of self" [88] }\end{array}$ & $\begin{array}{l}\text { The idea of collective hypnosis, a form of irrational } \\
\text { and unconscious social contagion }\end{array}$ \\
\hline Thorstein Veblen & 1899 & $\begin{array}{l}\text { Economics/ } \\
\text { Sociology }\end{array}$ & $\begin{array}{l}\text { Make comparisons with similar people who are } \\
\text { slightly better [89] }\end{array}$ & An instinct for emulation \\
\hline Georg Simmel & 1910 & Sociology & First researcher to consider social networks. & $\begin{array}{l}\text { "Impulse to sociability" and ramification in } \\
\text { loosely-knit networks [91] }\end{array}$ \\
\hline Sigmund Freud & 1922 & $\begin{array}{l}\text { Psychiatry/ } \\
\text { Medicine }\end{array}$ & $\begin{array}{l}\text { "A group is an obedient herd, which could never } \\
\text { live without a master" }\end{array}$ & $\begin{array}{l}\text { Also refers to "herd instinct". "The individual loses } \\
\text { his power of criticism, and lets himself slip into the } \\
\text { Affect... The cruder and simpler emotional } \\
\text { impulses are the more apt to spread through } \\
\text { a group in this way" [92] }\end{array}$ \\
\hline $\begin{array}{l}\text { John Maynard } \\
\text { Keynes }\end{array}$ & 1935 & Economics & Contagious "animal spirits" moving the market [94] & $\begin{array}{l}\text { Individuals do not process new information } \\
\text { efficiently as they don't know which information is } \\
\text { relevant. Conventional behaviour easily turns into } \\
\text { herd behaviour }\end{array}$ \\
\hline Muzafer Sherif & 1936 & Psychology & $\begin{array}{l}\text { Used autokinetic effect, an optical illusion to } \\
\text { illustrate that individuals use others' judgments to } \\
\text { converge with the social norms of the group [39] }\end{array}$ & $\begin{array}{l}\text { Social norms serve as a shared frame of reference, } \\
\text { with a rational attempt to make sense of social reality }\end{array}$ \\
\hline Solomon Asch & 1951 & Psychology & $\begin{array}{l}\text { Convergence in the famous line experiments } \\
\text { revealing pressure to conform to an erroneous } \\
\text { view [40] }\end{array}$ & $\begin{array}{l}\text { Rational attempts of individuals to make sense of } \\
\text { social reality to share group perceptions }\end{array}$ \\
\hline Serge Moscovici & 1969 & $\begin{array}{l}\text { Social } \\
\text { psychology }\end{array}$ & $\begin{array}{l}\text { Separated social influence from power relations. } \\
\text { Social influence theory assumes that cognitive } \\
\text { uncertainty about social reality causes conformity } \\
\text { in given situations [97] }\end{array}$ & $\begin{array}{l}\text { Social conflict leads to uncertainty and a willingness } \\
\text { to agree with conflicting viewpoints }\end{array}$ \\
\hline Mark Granovetter & 1973 & Sociology & $\begin{array}{l}\text { The Strength of Weak Ties interpersonal ties are } \\
\text { defined as information-carrying connections } \\
\text { between people [98] }\end{array}$ & $\begin{array}{l}\text { Social networks in diffusion processes, stressed the } \\
\text { importance of weak ties which permit diffusion }\end{array}$ \\
\hline $\begin{array}{l}\text { Sushil } \\
\text { Bikhchandani, } \\
\text { David Hirshleifer, } \\
\text { and Ivo Welch }\end{array}$ & 1992 & Economics & $\begin{array}{l}\text { By modelling showed that people could follow } \\
\text { others even if private information and motivations } \\
\text { suggested doing otherwise [38] }\end{array}$ & $\begin{array}{l}\text { Assumed incomplete information and rationality. } \\
\text { The number of others performing the action taken } \\
\text { as evidence that the others possessed better } \\
\text { information, yielding conformity and "informa- } \\
\text { tional } \\
\text { cascades" based on imperfect information }\end{array}$ \\
\hline $\begin{array}{l}\text { James Fowler } \\
\text { and Nicholas } \\
\text { A. Christakis }\end{array}$ & 2009 & $\begin{array}{l}\text { Political } \\
\text { Science }\end{array}$ & $\begin{array}{l}\text { Recent example of Social network methodology } \\
\text { [27] }\end{array}$ & Social networks (see Figure I in Box 1) \\
\hline
\end{tabular}

The study of herding has an extensive history and has come to be studied from a variety of perspectives and at distinct levels of analysis; the macro and micro, or more specifically, pattern-based and transmission-based levels, as captured by our classification (Figure 2). Although Tarde was the first to advocate the idea of the 'group mind' [90], as an explanatory principle of crowd psychology and herd behaviour, the actual phrase 'herd behaviour' was first introduced into English by the medic Trotter in 1908. Trotter developed a theory of the 'herd instinct' [99] an innate psychological dependency of humans on their social group. Although there is a broad consensus on the concept of herd behaviour, the history of the concept in the various fields indicates major theoretical differences with respect to both underlying assumptions and mechanisms. Herd mentality and behaviour have been a ubiquitous part of the portrayal of human behaviour since individuals began to construct tribes and migrate collectively. However, it is in the analysis of stock markets (particularly booms and busts) that herding has received most of the recent attention in the social sciences, with a focus on the 'irrational exuberance' [6] of investors. 


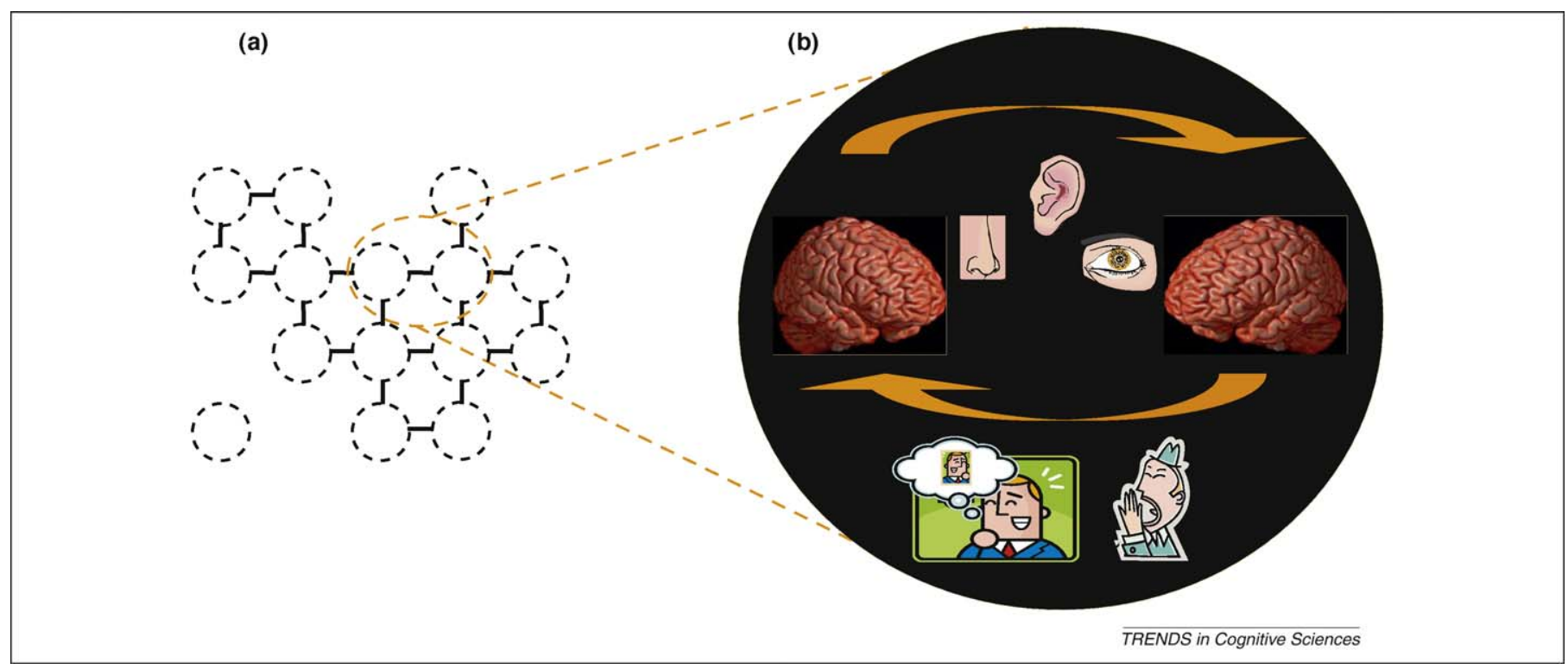

Figure 1. The two complementary perspectives of herding can be considered as a global/local distinction, with a focus on the pattern connecting individuals (Figure 1a), contrasted to that of the transmission of information that comprises it (Figure 1b).

herding also arises from the organizing relations of those parts, that is, by how the individuals are configured (Figure 1b). The pattern-based approach, adopted widely in fields such as Traffic Jam and Crowd analysis, financial markets, and social network analysis, emphasizes the static structure of the system and its relationships. It shows the dependencies among these components and takes the relationships between individuals as the primary unit for herding research and for the development of theory. However, a full understanding of herding behaviour requires the ability to 'shift' between the two levels represented in our framework. This distinction aids in the identification of contextual effects, that is, herding behaviour that is not apparent at the individual level. Moreover, the proposed framework indicates at which level different research questions could be appropriately addressed. For instance, there are some enquiries, such as whether herding is linear (that is, whether we can use conventional 'reductionist' approaches that look at the parts and employ superposition to investigate how they work together), which can only be addressed at the pattern level. In contrast, focusing on the affective and cognitive mental states of individuals, specifying the common and differential neural mechanisms of 'self' and 'other', or interpersonal face-to-face interactions [13] may reveal quite different aspects of herding from the insights arising out of the pattern-based level. These two levels are not mutually exclusive; both levels can cross-fertilize each other. Moreover we consider that increasing knowledge of the brain areas involved in social cognition (the capacity to understand people's behavioural intentions, social beliefs, and personality traits) [14] can inform patternbased herding analyses and constrain the vast space of relations that can potentially exist between actors.

\section{Pattern-based theories/models of herding behaviour: structure sets the herd?}

Pattern-based explanations treat individuals as units with certain simple, well-defined properties and modes of interaction (Figure 2, left branch). The terminology used in this class of models, such as 'critical mass', 'self-organized criticality' and 'epidemics', is inspired by models in either particle physics or epidemiology and shares a similar structure. Such models often come under the rubric of econophysics models of herding and are prevalent in finance [15].

Pattern-based approaches view herding (and social phenomena in general) in terms of the patterns of interaction among the agents, modelled as simple imitators, or as following basic heuristics. In other words, people are treated as units or atoms with certain simple, well-defined properties and modes of interaction that yield herding: the focus is patterns, not people [16]. The models generally rely on physical laws, distances and velocities rather than the emotional states of the herd. These approaches to multiagent phenomena are applied to many areas, naturally lending themselves to the explanation of phenomena, such as queuing, crowd and traffic interactions [17]. Cellular Automata models [18,19] and Ising models [20] are the most extreme examples of this abstract approach. Closely related are models of 'flocking' in animal behaviour (for excellent reviews see [21,22]), widely exhibited in biology by living creatures ranging from bacteria to birds. These models have been used to simulate human crowd behaviour $[17,23]$, social behaviour such as language emergence and evolution [24], as well as in attempts to elucidate the general concept of emergent phenomena [25].

The most intuitively understandable pattern-based perspective is social network analysis - this perspective employs the simplest of structures in which each node (a person) is attached via some tie to others. This approach has had an important influence in modern sociology (Box 1). Such studies have shown that happiness and obesity tend to spread through social networks in a manner analogous to a contagious disease [26,27] (Figure I in Box 1). Thinking in social network terms has progressed from being an evocative allegory [28-30] and has been extended to agent-based modelling approaches [31]. Social network 


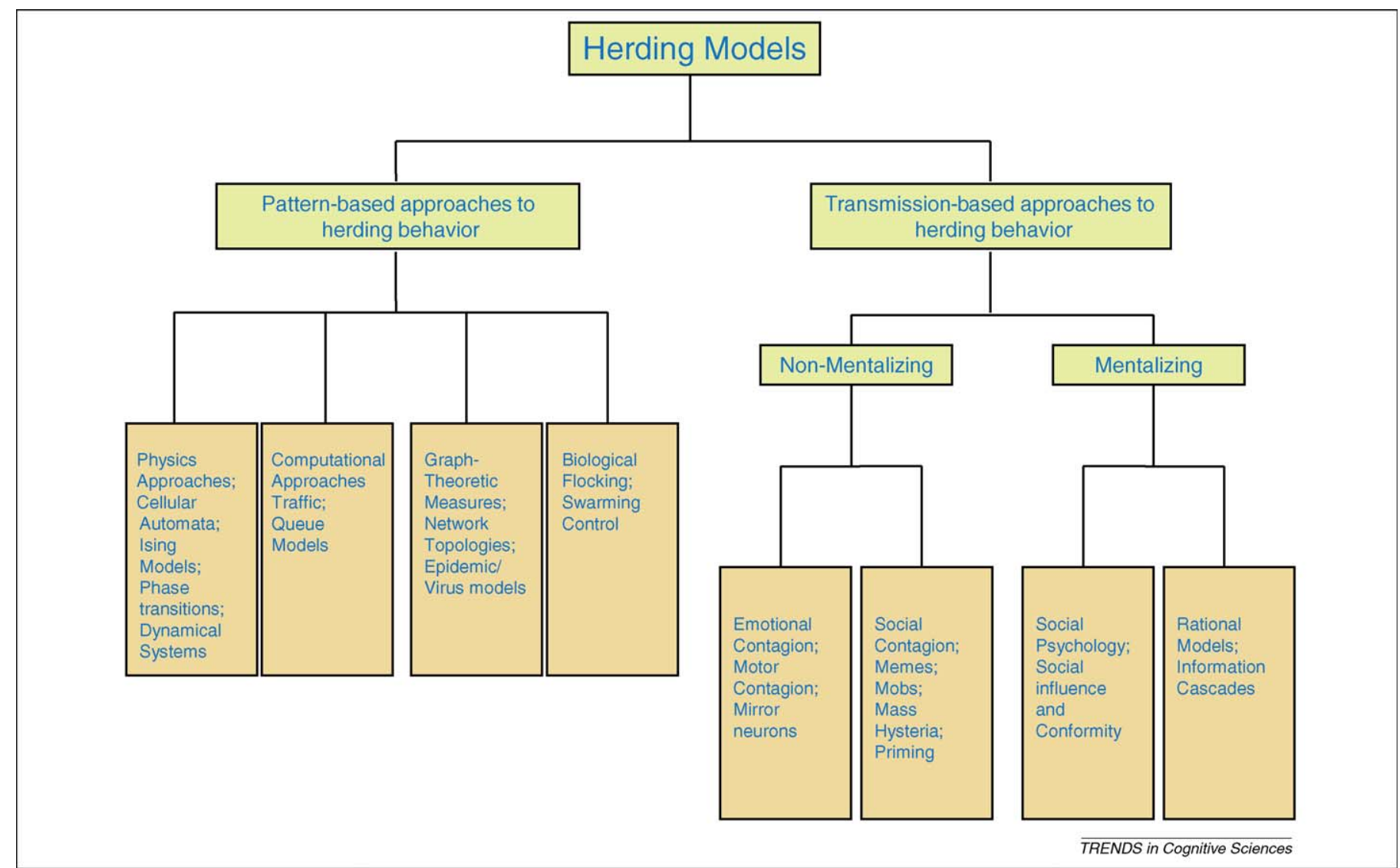

Figure 2. The underlying aim of this paper is to understand the mechanism of effective control in a distributed group without centralized coordination. In functional terms, how is the herding structure sustained without a direct control mechanism? The findings summarized in this paper indicate that this question can be addressed at two levels: transmission and pattern. Given suitable signals and rules, individuals can spontaneously self-organize themselves into herds. However, such a description would be incomplete if we did not understand how that was instantiated at the individual level, that is how are such signals encoded, stored and retrieved: in short the cognitive mechanisms of herding. The framework proposed in this paper demarcates in the first branch the approaches based on more pattern-based drivers (more mathematical and taking little account of the inner states of the individual agents). In the second branch, are the transmission mechanisms, the more 'mentality-based approaches, where emotion (at one end of the 'scale') and rationality come to the fore (however, this is not to say that there are no interactions or feedback mechanisms between the two).

analysis focuses on how the structure of other relationships affects individuals [32] rather than treating individuals as the fundamental unit, and allows epidemiological methods to be employed.

\section{Transmission mechanisms in herding: how do we broadcast?}

In contrast to the focus on patterns of interaction, the complementary transmission perspective seeks to unify and identify mechanisms of transfer of information in herding (as illustrated in the split within the right branch of Figure 2) by concentrating on the role of cognitive and affective components, particularly the effortless human capacity known as 'mentalizing' (the ability to explain and predict the behaviour of others by attributing to them independent mental states) [33]. A number of important theoretical distinctions can be used to classify different transmission mechanisms in human herding, including rational vs. emotional, automatic vs. controlled and conscious vs. unconscious. However, herding is a social tendency; an essential component of this behaviour is that it can incorporate beliefs about the herd. Individuals often converge by modelling behaviours and beliefs of the larger group within which they are embedded. Indeed most economic models are based on the assumption that single agents are able to view another agent's perspective [34].
People often explicitly attempt to infer others' beliefs, attitudes or preferences; and draw on these to help determine their own perspective [35]. As such, our sub-division reflects this key mentalizing facet. In Figure 2, the left subbranch under transmission-based approaches includes approaches that do not postulate mentalizing as a critical aspect of transmission. These approaches range from emotional contagion through to social contagion and priming. The right 'mentalizing' sub-branch encompasses social conformity and influence, culminating with rational processes through which the agent consciously and deliberately considers the information in the signals of others. Although the importance of the presence of others has been a mainstay of social psychology, since Le Bon's [36] claim that collective influence can almost mesmerize the individual, when herding is viewed from a rational stance it is generally considered in two flavours: informational and reputational (that is, peer pressure) [37]. Economists, in particular, have observed how groups of individually rational agents, each drawing on information about the choices of others can fall into collectively irrational 'informational cascades', which do not properly reflect the group's preferences. This assumes a utility-maximizing behaviour on the part of each agent [38] (Box 2).

There are, of course, other explicit drivers that may induce the alignment of the thoughts or behaviours of 


\section{Box 1. Social Network Analysis and convergence}

Perhaps one of the most exciting developments for understanding the elusive temporal-spatial characterization of herding behaviour, emblematic of the division that we have proposed in Figure 2, is Social Network Analysis (SNA). A social network is a social structure made of nodes (people) that are connected by one or more specific types of interdependency. SNA maps and measures the relationships and flow between these units, both visual and mathematical. The resulting graph-based structures are often very complex (Figure I) with the shape of a social network and its number of connections being crucial for the diffusion of information and herding [100]. A number of important social and economic phenomena have been studied as arising out of network effects where imperfect information is a key feature of human decision-making environments (information cascade Box 2).
Most social networks display substantial non-trivial topological attributes with complicated patterns of connection between their features of interest. From a herding perspective there are number of important metrics that range from cohesion to clustering coefficients. SNA provides a quantitative framework that can be used to characterize the herding structure both at the level of the individual and the population, aiding with the understanding of processes such as information transfer. Understanding the pattern of interactions in the network (i.e. who is connected to whom) can clarify the role of behavioural strategies.

In spite of their seemingly random nature, the topology of some graphs possess a number of universal scale-free characteristics [101] - it would be interesting to determine how this is related to the network characteristics of herding [102]
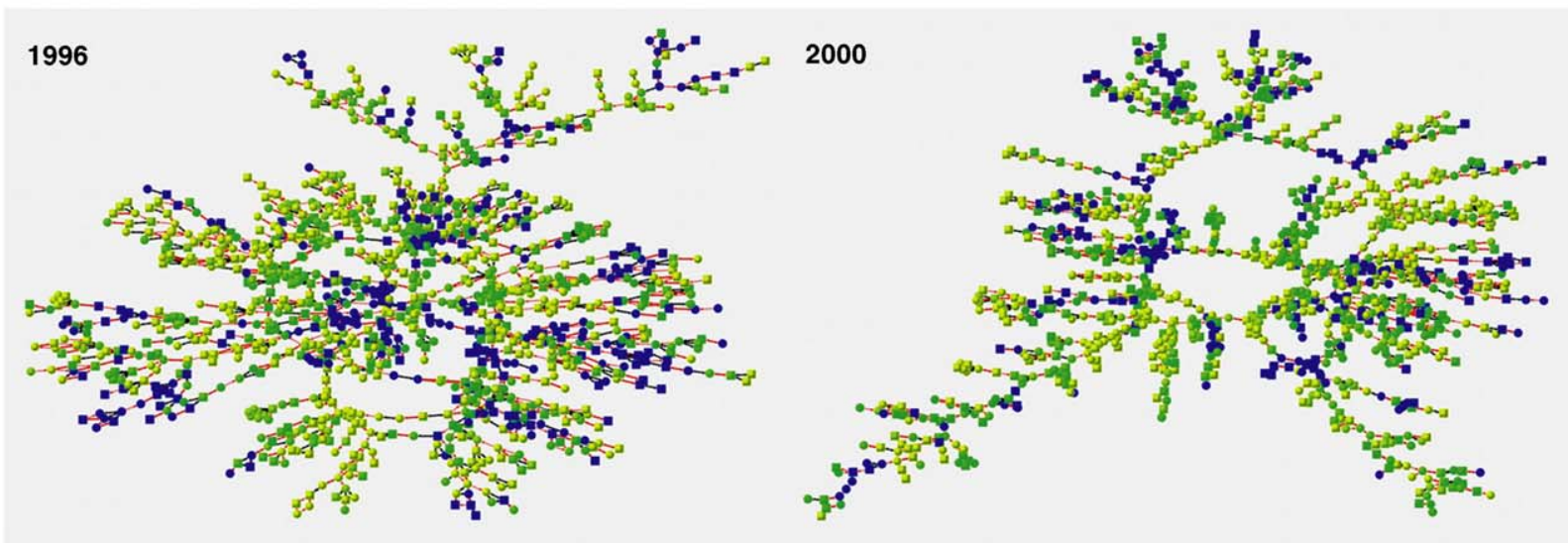

TRENDS in Cognitive Sciences

Figure I. An example of Social Network Analysis indicating alignment of state without centralized coordination are the Happiness clusters identified in the Framingham Heart [27] study. The researchers were able to recreate the social networks of 4739 Framingham participants whose happiness was measured using a standard assessment test.

The Graphs show the largest component (a group of individuals where each individual is connected by at least one path to every other individual) of friends, spouses and siblings in years 1996 and 2000. Each node denotes one person (circles denote female, squares denote male).

Inspection of the social network reveals that happy people tend to be connected to one another. The clusters of happy and unhappy people seen in the network are significantly larger than expected by chance. Happiness is dependent on the happiness of others to whom individuals are connected directly and indirectly, and requires close proximity to spread. For instance, when a happy individual lives within a mile of a friend, this increases the probability of that friend becoming happy by $25 \%$. Additionally, close physical proximity is crucial for happiness to spread. A person is $42 \%$ more likely to be happy if a friend who lives less than half a mile away becomes happy. The effect is only $22 \%$ for friends who live less than two miles away.

Over time, the results suggest that clusters of happiness originate from the spread of happiness and not just a tendency for people to associate with similar individuals. Although the findings are not uncontroversial (confusing correlation with causation [103]) they hint at the efficacy of the pattern-based approach.

individuals in a group (herd), through local interaction and without centralized coordination. Social psychological accounts, such as those of Sherif [39], Asch [40] or Latané [41], indicate mechanisms that are consistent with herding and contagion under a variety of conditions. Social influence, real or imagined, of others can have a measurable impact, ranging from obedience and compliance through to conformity (for a useful review [42]), but generally the latter imply some awareness of the act of alignment. This boundary between self and other is where social neuroscience can perhaps make a valuable contribution to the investigation of how the individual's perception [43] and the borders of self are affected by the group (Box 3). Social psychologists in particular have studied this as the process of de-individuation, and have addressed how the loss of a person's sense of individuality can reduce normal constraints against deviant behaviour. De-individuation is generally conceived of as a collective phenomenon, where anonymity and reduced feelings of individual responsibility provide a mechanism for situational forces to collec- tively drive behaviour [44] immersing the individual into the group or herd.

Although herding and its consequences may arise from active choice, responses often occur without awareness, hence the key role of mentality in herding. Presumably, these and other Theory of mind factors can be manipulated in the laboratory.

The most researched example of the non-mentalizing approach in describing transmission in human herding is that of emotional contagion. Emotional contagion involves an involuntary spread of feeling without any conscious awareness of where the feeling initially originated [45] and without necessarily requiring interpersonal empathy. For example, a child's emotion, be it excitement or a tantrum, can rapidly influence the emotion of others, generating a group of rowdy and energetic children. Adults too can experience such contagion, as when one can automatically pick up the excitement in a crowd or audience. However, unlike empathy, emotional contagion does not require understanding another's emotion and is largely involuntary, a 


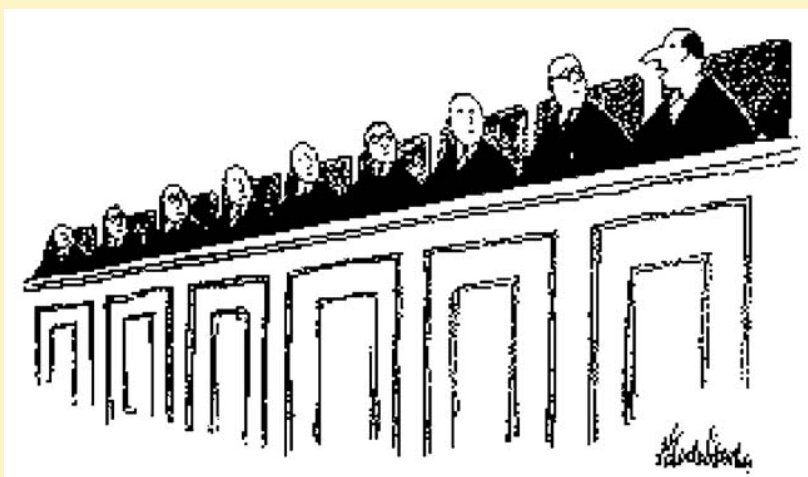

"Well heck! If all you smart cookies agree, who am I to dissent?" The New Yorker Magazine (c) 1972

A growing body of literature has highlighted the importance of information cascades in economics and the social sciences [104,105]. Information cascades nicely illustrate the rational approach that economists have applied to herding, in contrast to that of social psychologists. The mechanism is simple and, whereas there are more sophisticated models (e.g. based on networks [106]; Box 1), the intuitions revealed by the canonical model are useful [38], permitting the examination of the role of public information in correctly estimating the true state of the world. A cascade is a process by which people influence one another, such that participants ignore their private knowledge and follow instead the publicly stated judgments of others.

In the modern interconnected environment, with its abundant communications systems, information cascades are predicted to occur regardless of the plenitude of information available and despite the common interest of the agents.

Early models were known by different terms: bandwagons, herding and path-dependent choices. Under the term information cascade, it is assumed that agents choose in sequence and are influenced by rational consideration of the observed choices of earlier agents.

The crucial point is that those involved in a cascade do not reveal what they know. As a consequence, the group does not obtain important information. The basic mechanism is the following:

1. Consider a deliberating jury that is deciding whether a defendant should be subject to a guilty verdict.

2. Let us also assume that the jurors are announcing their views in sequence, in a temporal queue, and that each juror knows his or her place in that queue. Each juror, from their own recollection of the evidence and the jury instructions, has some private information (often called a private signal) about what should be done. Additionally, each juror also pays attention, reasonably well, to the judgments of others (often called a public signal).

3. The first juror makes a decision between the two mutually exclusive outcomes, although imperfectly informed (that is the agent is unsure of the 'true' status of the defendant). However, the first juror's pronouncement is public and observed by all.

4. For the second juror a mentalizing process occurs whereby this person observes the first juror's choice (and infers their private information 'signal' or opinion) and rationally combines this with their own opinion (in a Bayesian manner).

5. An 'information cascade' occurs when the first few jurors coincide in such a way that it is optimal for each of the subsequent individuals to ignore his or her opinion or belief about the guilt of the defendant and follow the established pattern. If a small number of agents accidentally make the same decisions, then it is easily shown by Bayes' rule that an agent who observes such public information should ignore their private information and follow their predecessors' decisions. The cascade rapidly reaches a 'tipping point' at which they rationally disregard their private information.

It is a 'good cascade' if the prediction made by the jurors corresponds to a true state of the world, i.e. the defendant is 'truly guilty' and conversely 'bad' if it does not. If this occurs, there exists a social problem: jurors who are in the cascade do not disclose the information that they privately hold.

This behaviour is sufficiently general to have occurred in a number of domains from military courts [107] to the blogosphere [108].

A strong form of contagion is termed hysterical contagion (also termed mass hysteria, collective hysteria or even mass psychogenic illness). A common manifestation of mass hysteria occurs when a group of people (falsely) believe that they are suffering from a similar disease or ailment [53-56]. Such manifestations have been reported as far back as 1374 (with dancing mania reaching such an extreme that it caused deaths) [57]. Other manifestations of the dark side of social contagion are displayed in mobs, riots and hooliganism [58]. These latter phenomena highlight the importance of a framework in organizing different approaches, as they indicate examples of behaviour which most likely draw upon both mentalizing and non-mentalizing drivers.

There is, of course, another example of an implicit effect, well researched by psychologists, which has applications for herding, namely priming: another example of a nonmentalizing phenomenon. People can be primed into certain forms of similar behaviour, with primes ranging from smells [59], everyday objects [60], the surroundings [61], to the performance of activities such as marching or dancing in unison which increase loyalty to the group $[62,63]$. More worryingly, on a larger scale, the news media $[64,65]$ implicitly influence the public, creating mass movements of the herd that are invisible to the individual. 


\section{Box 3. Questions for future research}

- When is herding adaptive in evolutionary terms? Might there really be a genetically based 'herd instinct'? How would this be implemented in cortical structures?

- What is the balance between herding and deliberate choice in determining our everyday thoughts and actions? Does this require inhibitory processes? Can we interfere with these processes with 'tools' such as Transcranial Magnetic Stimulation (TMS) in ways that are consistent with mentality and non- mentality based drivers of herding?

- Can the principal flavours of herding, emotional herding and rational herding (or apparent rationality) be distinguished by neuroimaging or by using experimental psychology paradigms such as cognitive load (which should increase contagion but reduce the effects of public information)?

- In a related theme, does the presence of social disorders like Autism Spectrum Disorders (ASD) affect herding behaviour? How is the 'herd' perceived and processed neurally if there are difficulties in 'other' representations?

- Can different herding mechanisms (e.g. those involving contagion vs. mentalizing) be distinguished by experiment or by observing functional brain activity?

- What kinds of environments induce herding behaviour (e.g. the internet)?

\section{What can social neuroscience say?}

A point of interaction between these two levels concerns the biological mechanisms that underlie herding. Social neuroscience is ideally positioned to connect these levels. Social structures may be emergent organizations beyond the individual, yet these emergent organizations require biological systems in the individual to create them $[66,67]$. Furthermore, there is a large body of work on imitation [68]. Mirror neurons (nerve cells that fire when we carry out an action, or watch someone else carry out a similar action) may also play a role in this interaction between the individual and the herd. Neural evidence seems to support this idea as a promising line of research. There are, as yet, few studies investigating the neurobiological correlates of herding mentality, conformity [43,69] and emotional contagion [70,71]. However, the evidence so far is promising; for example, it demarcates how emotion circuitry diverges in the adolescent male and female brain under peer approval [72] and rejection [73].

There are many areas in which the cognitive neuroscience 'toolbox' can be applied to research in herding. For example, neuroimaging could provide evidence for reinforcement models of information cascades [74]. There may also be analogies of quorum sensing (from ethology) in human herding. The communication of chemosensory signals between conspecifics has been well documented in many vertebrates and invertebrates, and as such provides a transmission mechanism for the non-mentalizing approaches to herding. Indeed, in a recent study, pre-exam sweat had a specific effect on brain activity, correlating with areas involved in empathy and those that process social and emotional signals [75].

Combining the methods of neuroscience and the diverse approaches presented in Figure 2 can generate powerful tools for studying the brain processes behind human herding. Novel neuroimaging techniques (scanning many individuals at a time) could be used to capture brain-based correlates of herding [76], whereas the emerging field of neuroeconomics $[77,78]$ offers the possibility of characterizing and building biological models of herding (such as the recent imaging study based on a model from economics the 'beauty contest' game - which permits the investigation of how a player's mental processing incorporates the thinking process of others in strategic reasoning [79]).

\section{Concluding remarks and future directions}

The concept of herding has been evoked in many different contexts, ranging from mass hysteria in neurology [56] to the diffusion of innovations in economics and to the propagation of ideas [80]. These appeals to collective behaviour all imply that certain forms of behaviour go beyond the individual, but different disciplines yield somewhat dissimilar accounts of the mechanisms of herding. To discern structure within this array of approaches requires a broad integrative viewpoint. The framework presented here, similar to other integrative approaches in cognitive psychology [81], has heuristic as well as integrative potential. It presents scaffolding for organizing the questions that can be addressed about herding and the common and diverse mechanisms that underlie it across domains. The proposed classification invites specific interdisciplinary questions to be addressed (see also Box 3). For instance, a pertinent case would be the boundary specification problem of a herd. Dunbar has suggested that the typical size of a social network is restricted to around 150 people due to possible limits in the capacity of the human communication channel [82]. How do pattern models integrate this with the limits of cognitive capacity?

In the group environment we are exposed to ever shifting emotional messages and are influenced by the social situation and other agents. The convergence upon a single mood or emotion can elicit herd behaviour in which the agents are connected and process stimuli in a similar manner. How stable this contagion is, its neural mechanisms and the role of rational 'top-down' factors remain unclear.

Diffusion theory explores social networks and their role in influencing the spread of new ideas and practices. How do authority figures or 'hubs' transmit their information in the more spatial-based transmission models, and can knowledge of cognitive biases or biological limitations in processing influence or provide more accurate parameters for these descriptions?

Allying the methods of cognitive neuroscience with the pattern-based and transmission-based perspectives on herding creates both interesting hypotheses and predictions concerning areas of activation associated with selfand other-processing and how the individual transmits (and encodes) information from/to the herd. Interesting herding patterns can be expected to arise within biological constraints that neuroimaging can elucidate, which in turn could provide insight into factors ranging from the rationality of herds [83] to the role of mentalizing and proximity [84].

One wonders, in this internet age with the increasing ease of sharing information and ideas [85], and with ever proliferating points of contact between people, whether we will be more susceptible to herding. However, with modern 
experimental data tracking techniques permitting the analysis of individuals in a top-down manner [86] and neuroscientific methods such as imaging in a bottom-up manner [71], more than ever the fields of social cognition and social neuroscience can play an important role in exploring the ubiquitous yet sometimes disquieting, interaction between the individual and the herd.

\section{References}

1 Goldstone, R.L. and Janssen, M.A. (2005) Computational models of collective behavior. Trends Cogn. Sci. 9, 424-430

2 Richerson, P.J. and Boyd, R. (2005) Gene-Culture Coevolution and the Evolution of Social Institutions. In Better than Conscious? Decision Making, the Human Mind, and Implications for Institutions (Engel, C. and Singer, W., eds), pp. 305-324, MIT Press

3 Sornette, D. et al. (2009) The 2006-2008 oil bubble: Evidence of speculation, and prediction. Physica A - Stat. Mech. Applic. 388, 1571-1576

4 Shiller, R.J. (2000) Irrational exuberance, Princeton University Press

5 Shiller, R.J. (2002) Bubbles, human judgment, and expert opinion. Fin. Analysts J. 58, 18-26

6 Shiller, R.J. (2008) The subprime solution: how today's global financial crisis happened and what to do about it, Princeton University Press

7 Akerlof, G.A. and Shiller, R.J. (2009) Animal spirits: how human psychology drives the economy, and why it matters for global capitalism, Princeton University Press

8 Kumar, M. (2007) A Journey into the Bleeding City: Following the Footprints of the Rubble of Riot and Violence of Earthquake in Gujarat, India. Psychol. Dev. Soc. 19, 1-36

9 Battaglini, M. (2005) Sequential voting with abstention. Games Econ. Behav. 51, 445-463

10 Salganik, M.J. et al. (2006) Experimental Study of Inequality and Unpredictability in an Artificial Cultural Market. Science 311, 854 856

11 Chen, Y.F. (2008) Herd behavior in purchasing books online. Comput. Hum. Behav. 24, 1977-1992

12 Hamilton, W.D. (1971) Geometry for the selfish herd. J. Theor. Biol. $31,295-311$

13 Schulte-Ruther, M. et al. (2007) Mirror neuron and theory of mind mechanisms involved in face-to-face interactions: A functional magnetic resonance imaging approach to empathy. J. Cogn. Neurosci. 19, 1354-1372

14 Van Overwalle, F. (2009) Social Cognition, and the Brain: A MetaAnalysis. Hum. Brain Mapping 30, 829-858

15 Rickles, D. (2008) Econophysics and Financial Market Complexity, In Handbook of the Philosophy of Science, Vol.10: Philosophy of Complex Systems, Elsevier

16 Buchanan, M. (2007) The Social Atom: Why the Rich Get Richer, Cheaters Get Caught, and Your Neighbor Usually Looks Like You, Bloomsbury Publishing

17 Dyer, J.R.G. et al. (2008) Consensus decision making in human crowds. Anim. Behav. 75, 461-470

18 Bartolozzi, M. and Thomas, A.W. (2004) Stochastic cellular automata model for stock market dynamics. Phys. Rev. e 69

19 Kirchner, A. and Schadschneider, A. (2002) Simulation of evacuation processes using a bionics-inspired cellular automaton model for pedestrian dynamics. Physica A - Stat. Mech. Applic. 312, 260-276

20 Borghesi, C. and Bouchaud, J.P. (2007) Of songs and men: a model for multiple choice with herding. Qual. and Quantity 41, 557-568

21 Sumpter, D.J.T. (2006) The principles of collective animal behaviour. Philos. Trans. R. Soc. B -Biol. Sci. 361, 5-22

22 Couzin, I. (2007) Collective minds. Nature 445, 715

23 Dyer, J.R.G. et al. (2009) Leadership, consensus decision making and collective behaviour in humans. Philos. Trans. R. Soc. B -Biol. Sci. 364, 781-789

24 Cucker, F. et al. (2004) Modeling Language Evolution. Foundations of Comput. Math. 4, 315-343

25 Cucker, F. and Smale, S. (2007) On the mathematics of emergence. Jpn. J. Math. 2, 197-227

26 Christakis, N.A. and Fowler, J.H. (2007) The spread of obesity in a large social network over 32 years. N. Engl. J. Med. 357, 370-379
27 Fowler, J.H. and Christakis, N.A. (2008) Dynamic spread of happiness in a large social network: longitudinal analysis over 20 years in the Framingham Heart Study. BMJ 337, p. a2338

28 Schwammle, V.et al. (2007) Different topologies for a herding model of opinion. Phys. Rev. e 75

29 Natalie, S. and Petr, S. (2007) Technology adoption and herding behavior in complex social networks. Working Papers Charles University Prague, Faculty of Social Sciences, Institute of Economic Studies IES 2007/08, revised May 2008

30 Watts, D.J. (2007) A twenty-first century science. Nature 445, 489

31 Alfarano, S. and Milakovic, M. (2009) Network structure and Ndependence in agent-based herding models. J. Econ. Dynamics \& Control 33, 78-92

32 Choi, S. et al. (2005) Behavioral Aspects of Learning in Social Networks: An Experimental Study. In Advances in Applied Microeconomics, Vol. 13, Behavioral and Experimental Economics, (Morgan, J., ed.), Berkeley, Calif.: BE Press

33 Frith, C.D. and Frith, U. (2006) The neural basis of mentalizing. Neuron 50, 531-534

34 Singer, T. and Fehr, E. (2005) The neuroeconomics of mind reading and empathy. Am. Econ. Rev. 95, 340-345

35 Frith, C.D. and Frith, U. (2008) Implicit and Explicit Processes in Social Cognition. Neuron 60, 503-510

36 Le Bon, G. (1896) The Crowd. A study of the popular mind, T.F. Unwin

37 Barton, A.M. (2009) Application of Cascade Theory to Online Systems: A Study of Email and Google Cascades. Minn. J. Law, Sci. \& Tech., Villanova Law/Public Policy Research Paper No. 2009-18

38 Bikhchandani, S. et al. (1992) A Theory of Fads, Fashion, Custom, and Cultural-Change As Informational Cascades. J. Pol. Econ. 100, 992 1026

39 Sherif, M. and Murphy, G. (1936) The psychology of social norms, Harper \& Brothers

40 Asch, S.E. (1956) Studies of independence and conformity: A minority of one against a unanimous majority. Psychol. Monographs, 70 (Whole no. 416)

41 Latané, B. (1996) Dynamic Social Impact: The Creation of Culture by Communication. J. Commun. 46, 13-25

42 Cialdini, R.B. and Goldstein, N.J. (2004) Social influence: Compliance and conformity. Annu. Rev. Psychol. 55, 591-621

43 Berns, G.S. et al. (2005) Neurobiological Correlates of Social Conformity and Independence During Mental Rotation. Biol. Psychiatry 58, 245-253

44 Zimbardo, P.G. (2004) A Situationist Perspective on the Psychology of Evil: Understanding How Good People Are Transformed into Perpetrators. In The social psychology of good and evil (Miller, A.G., ed.), Guilford Press

45 WispeÌ, L. (1991) The psychology of sympathy, Plenum Press

46 Derks, D. et al. (2008) The role of emotion in computer-mediated communication: A review. Comput. Hum. Behav. 24, 766-785

47 Gervais, M. and Wilson, D. (2005) The Evolution and Functions of Laughter and Humor: A Synthetic Approach. Q. Rev. Biol. 80, 395-430

48 Gallup, A.C. and Gallup, J. (2008) Yawning and thermoregulation. Physiol. \& Behav. 95, 10-16

49 Schürmann, M. et al. (2005) Yearning to yawn: the neural basis of contagious yawning. Neuroimage 24, 1260-1264

50 Frith, C.D. and Frith, U. (2007) Social Cognition in Humans. Curr. Biol. 17, R724-R732

51 Barsade, S.G. (2002) The ripple effect: Emotional contagion and its influence on group behavior. Administrative Sci. Q. 47, 644-675

52 Hatfield, E. et al. (1994) Emotional contagion, Cambridge University Press

53 Adams, G. and Salter, P.S. (2007) Health Psychology in African Settings: A Cultural-psychological Analysis. J. Health Psychol. 12, $539-551$

54 Balaratnasingam, S. and Janca, A. (2006) Mass hysteria revisited. Curr. Opin. Psychiatry 19, 171-174

55 Jones, T.F. et al. (2000) Mass Psychogenic Illness Attributed to Toxic Exposure at a High School. N. Engl. J. Med. 342, 96-100

56 Roach, E.S. and Langley, R.L. (2004) Episodic neurological dysfunction due to mass hysteria. Arch. Neurol. 61, 1269-1272

57 Waller, J. (2009) The art of medicine A forgotten plague: making sense of dancing mania. Lancet 373, 624-625 
58 Russell, G.W. (2004) Sport riots: A social-psychological review. Aggression and Violent Behav. 9, 353-378

$59 \mathrm{Li}$, W. et al. (2007) Subliminal smells can guide social preferences. Psychol. Sci. 18, 1044-1049

60 Kay, A.C. et al. (2004) Material priming: The influence of mundane physical objects on situational construal and competitive behavioral choice. Organizational Behav. Hum. Decision Processes 95, 83-96

61 Keizer, K. et al. (2008) The Spreading of Disorder. Science 322, 16811685

62 Seger, C.R. et al. (2009) Subtle activation of a social categorization triggers group-level emotions. J. Exp. Soc. Psychol.,45, 460-467 doi: $10.1016 /$ j.jesp.2008.12.004

63 Wiltermuth, S.S. and Heath, C. (2009) Synchrony and Cooperation. Psychol. Sci. 20, 1-5

64 Doms, M. and Morin, N. (2004) Consumer Sentiment, the Economy, and the News Media. Federal Reserve Bank of San Francisco (July)

65 Cheng, A.T.A. et al. (2007) The influence of media reporting of the suicide of a celebrity on suicide rates: a population-based study. Int. J. Epidemiol.,36, 1229-1234 doi: 10.1093/ije/dym196

66 Cacioppo, J.T. (2002) Social neurosciences understanding the pieces fosters understanding the whole and vice versa. Am. Psychol. 57, 819831

67 Christiansen, M.H. and Chater, N. (2008) Language as shaped by the brain. Behav. Brain Sci. 31, 489-508

68 Hurley, S.L. and Chater, N. (2005) Perspectives on imitation: from neuroscience to social science, MIT Press

69 Klucharev, V. et al. (2009) Reinforcement Learning Signal Predicts Social Conformity. Neuron 61, 140-151

70 Wild, B. et al. (2001) Are emotions contagious? Evoked emotions while viewing emotionally expressive faces: quality, quantity, time course and gender differences. Psychiatry Res. 102, 109-124

71 Nummenmaa, L. et al. (2008) Is emotional contagion special? An fMRI study on neural systems for affective and cognitive empathy. NeuroImage 43, 571-580

72 Guyer, A.E. et al. (2009) Probing the neural correlates of anticipated peer evaluation in adolescence. Child Dev. 80, 1000-1015 (16)

73 Masten, C.L. et al. (2009) Neural correlates of social exclusion during adolescence: understanding the distress of peer rejection. Soc. Cogn. Affect Neurosci. 4, 143-157

74 Kawagoe, T. and Sasaki, S. (2006) Is Ignoring Public Information Best Policy? Reinforcement Learning. In Information Cascade (Braun, C., ed.), pp. 191-199, Berlin, Springer

75 Prehn-Kristensen, A. et al. (2009) Induction of Empathy by the Smell of Anxiety. PLoS ONE 4, e5987

76 Montague, P.R. et al. (2002) Hyperscanning: Simultaneous fMRI during linked social interactions. NeuroImage 16, 11591164

77 Fehr, E. and Camerer, C.F. (2007) Social neuroeconomics: the neural circuitry of social preferences. Trends Cogn. Sci. 11, 419-427

78 Sanfey, A. and Dorris, M. (2009) Games in Humans and Non-human Primates: Scanners to Single Units. In Neuroeconomics (Paul, W.G. et al., eds), pp. 63-80, Academic Press

79 Coricelli, G. and Nagel, R. (2009) Neural correlates of depth of strategic reasoning in medial prefrontal cortex. Proc. Natl. Acad. Sci. U.S.A. 106, 9163-9168

80 Heath, C. et al. (2001) Emotional selection in memes: The case of urban legends. J. Pers. Soc. Psychol. 81, 1028-1041

81 Kenrick, D.T. et al. (2002) Dynamical Evolutionary Psychology: Mapping the Domains of the New Interactionist Paradigm. Pers. Soc. Psychol. Rev. 6, 347-356
82 Dunbar, R.I.M. (1996) Grooming, gossip, and the evolution of language, Harvard University Press

83 Drury, J. et al. (2009) Everyone for themselves? A comparative study of crowd solidarity among emergency survivors. Br. J. Soc. Psychol. $48,487-506$

84 Novelli, D. et al. (2009) Come together: Two studies concerning the impact of group relations on 'personal space'. Br. J. Soc. Psychol. Epub available on line June 11, 2009, doi:10.1348/014466609X449377

85 Friedman, T.L. (2005) The world is flat a brief history of the globalized world in the twenty-first century, Allen Lane

86 Pentland, A. (2007) On the Collective Nature of Human Intelligence. Adapt. Behav. 15, 189-198

87 Smith, A. (1759) The theory of moral sentiments, A. Millar

88 Le Bon, G. (1903) The crowd a study of the popular mind, T.F. Unwin

89 Veblen, T. (1899) The theory of the leisure class an economic study of institutions, The Macmillan Company

90 Tarde, G.d and Parsons, E.W.C. (1903) The laws of imitation, H. Holt and Company

91 Simmel, G. and Hughes, E.C. (1949) The Sociology of Sociability (translated from Soziologie der Geselligkeit by Hughes, opening speech of the German Sociological Society, 1910). Am. J. Sociol. 55, 254-261

92 Freud, S. (1922) Group psychology and the analysis of the ego (English translation from Massenpsychologie und Ich-Analyse), The International Psychoanalytical Press

93 Allport, F.H., (1924) Response to Social Stimulation in the Crowd. In Social psychology Chapter 11. 260-291, Houghton Mifflin

94 Keynes, J.M. and Royal Economic Society (1936) The general theory of employment, interest and money. Macmillan

95 Penrose, L.S. (1952) On the objective study of crowd behaviour, H.K. Lewis

96 Rogers, E.M. (1962) Diffusion of innovations, Free Press

97 Moscovici, S. et al. (1969) Influence of a consistent minority on the responses of a majority in a color perception task. Sociometry 32,365 380

98 Granovetter, M.S. (1973) The Strength of Weak Ties. Am. J. Sociol. 78,1360

99 Trotter, W. (1908) Herd instinct and its bearing on the psychology of civilised man, Sherratt \& Hughes

100 Garcia, M.S. and Tor, A. (2009) The N-Effect: More Competitors, Less Competition. Psychol. Sci. 20, 871-877

101 Newman, M.E.J. et al. (2006) The structure and dynamics of networks 18, Princeton University Press

102 Lazer, D. et al. (2009) Computational Social Science. Science 323, 721723

103 Cohen-Cole, E. and Fletcher, J.M. (2008) Detecting implausible social network effects in acne, height, and headaches: longitudinal analysis. BMJ 337, a2533

104 Sunstein, C.R. (2005) Group judgments: Statistical means, deliberation, and information markets. N. Y. Univ. Law Rev. 80, 962-1049

105 Guarino, A. and Cipriani, M., (2008) Herd Behavior in Financial Markets: An Experiment with Financial Market Professionals. SSRN eLibrary

106 Leskovec, J. et al. (2006) Patterns of Influence in a Recommendation Network. Adv. Knowl. Discov. Data Mining 3918, 380-389

107 Farnsworth, W. (2007) The legal analyst: a toolkit for thinking about the law, University of Chicago Press

108 Leskovec, J. et al. (2007) Cascading Behavior in Large Blog Graphs http://arxiv.org/abs/0704.2803 